\title{
O PROJETO EDUCACIONAL DA UNIÃO CATÓLICA MILITAR E O SEU PAPEL DE APARELHO PRIVADO DE HEGEMONIA NA DIFUSÃO DE UM PENSAMENTO CONSERVADOR TEOCRÁTICO
}

\author{
Pedro Henrique Lessa Torres ${ }^{\mathrm{i}}$
}

\begin{abstract}
Resumo: Através da Revista $O$ Centurião e do intelectual conservador católico Jackson de Figueiredo, analisou-se o projeto educacional da União Católica Militar (UCM), uma associação de militares católicos, surgida na década de 1920, com o propósito maior de combater o movimento tenentista, através da difusão de valores morais católicos entre os membros das forças armadas. Almejava-se um maior grau de disciplina e coesão. A UCM recebeu apoio da cúpula do exército, assim como de altas autoridades eclesiásticas da Igreja Católica, atuando como um aparelho privado de hegemonia (GRAMSCI,1978) que difundiu uma escala de ideais conservadores por todo o país e colocou em perigo a laicidade do Estado Brasileiro.
\end{abstract}

Palavras-chave: Laicidade; Hegemonia; Intelectuais

\section{THE EDUCATIONAL PROJECT OF THE CATHOLIC MILITARY UNION AND ITS ROLE AS A PRIVATE APPARATUS OF HEGEMONY IN THE DIFFUSION OF A CONSERVATIVE THEOCRATIC THOUGHT}

\begin{abstract}
Through the magazine $O$ Centurião and the conservative Catholic intellectual Jackson de Figueiredo, the educational project of the Military Catholic Union (UCM) was analyzed, an association of Catholic military men, born in the 1920s, with the greater purpose of combating the tenente movement, through the spread of Catholic moral values among members of the armed forces. A greater degree of discipline and cohesion was desired. The UCM received support from the army leadership, as well as high ecclesiastical authorities of the Catholic Church, acting as a private apparatus of hegemony (GRAMSCI, 1978) that spread a scale of conservative ideals throughout the country and endangered the laity of the state Brazilian.
\end{abstract}

Keywords: Laicity; Hegemony; Intellectuals

\section{Introdução}

Este trabalho apresentará o surgimento da União Católica Militar (UCM), uma associação de militares católicos fundada em 1926, mas cuja origem remonta ao ano de 1922. A relevância deste empreendimento se deve ao fato de que esta associação desenvolveu um projeto educacional que se tornou hegemônico ${ }^{\text {ii }}$ no campo militariii , consolidando uma mentalidade que em 1969 culminou na disciplina de Educação Moral e Cívica (EMC). Através da EMC difundiram-se pelo país valores conservadores vinculados ao catolicismo e ao nacionalismo que influenciam o campo educacional até os dias atuais ${ }^{\text {iv }}$. 
A finalidade deste artigo é delimitar do ponto de vista teórico o que representa a $\mathrm{UCM}^{\mathrm{v}}$, assim como contextualizar o seu surgimento como fazendo parte de um movimento político-filosófico denominado Conservadorismo ${ }^{\mathrm{vi}}$.

\section{A origem da UCM}

A UCM, conforme o disposto no regulamento criado na ocasião da sua fundação, é uma associação brasileira de militares católicos, fundada em 1926, com o propósito de reunir os católicos do exército e demais forças militares (marinha, bombeiros, policiais e afins) para difundir a instrução religiosa católica, fazer amar o exército como esteio da nação e propagar em todos os recantos do país a fidelidade às leis e autoridades constituídas (CENTURIÃO, 1928a, p.10).

O surgimento da UCM suscita muitas questões. Eis algumas: Por que surgiu uma associação de militares católicos na década de 1920? Por que não surgiu antes? Ou, por que não surgiu depois? O que significa especificamente difundir a instrução religiosa católica? Ou seja, com quais finalidades se pretende difundir essa instrução religiosa católica? Como a Igreja católica se relaciona com esta nova instituição? Como a alta hierarquia militar enxerga essa iniciativa? Como se pretendia difundir a instrução católica? Como os agentes públicos envolvidos nesta associação enxergam a separação entre a Igreja e o Estado? Indo ainda mais fundo, como a UCM entende, no momento do seu surgimento, a questão da laicidade?

Para responder a contento estas perguntas é preciso, no mínimo, mencionar um periódico e um intelectual $^{\mathrm{vii}}$ de grande participação durante o período: o periódico chama-se o Centurião e o intelectual chama-se: Jackson de Figueiredo.

O Centurião foi uma revista editada pela própria UCM entre os anos de 1928 e 1929. A UCM também editou outros periódicos, mas para os fins deste trabalho, nos circunscreveremos apenas ao Centurião.

O Centurião foi o primeiro órgão oficial de divulgação das ideias da UCM. O seu diretor era o coronel Jorge Pinheiro e os seus principais redatores eram o coronel Benjamim Raphael da Fonseca e o capitão Paulo Joaquim Lopes (CENTURIÃO, 1928a, p. 1). Foram publicados doze exemplares, dos quais restam preservados apenas onze. O primeiro número está desaparecido. Nestes onze exemplares existentes, encontramos 127 artigos e mais de duas centenas de notas avulsas. O seu fim, em 1929, se deu por dificuldades financeiras. (CENTURIÃO, 1929, p. 5).

Temos em O Centurião a principal fonte de estudo acerca dos anos iniciais da UCM. Contudo, este periódico não se constitui num mero relatório das ações empreendidas pela associação.

O Centurião é uma janela a partir da qual podemos visualizar toda a rede de relações que sustentou o surgimento, a manutenção e crescimento da UCM. E mais, através desta janela também podemos observar 
os fundamentos filosóficos e políticos por trás da associação, o que não é banal, haja vista que conforme o mencionado na introdução, os valores ali engendrados circulam até hoje em nossa sociedade interferindo no debate educacional.

Nos artigos analisados, sobressai um nome: Jackson de Figueiredo. Este homem é apontado como o pensador que embasa as ideias expostas na revista, o farol que ilumina o caminho seguido pelos associados.

São nas suas obras que encontramos as explicações sobre a origem e finalidade da UCM. Em especial em um livro intitulado A Reação do Bom Senso (FIGUEIREDO,1922), encontramos informações mais claras do que no próprio Centurião. Nesse sentido, nos cabe questionar, quem foi Jackson?

Jackson de Figueiredo foi um sergipano nascido em 1891 e sua existência influenciou os rumos filosóficos e políticos do país porque sob as asas de Dom Leme, ele criou e dirigiu o Centro Dom Vital e a revista $A$ Ordem. Estas instituições congregaram um grande número de intelectuais católicos que não somente influíram nos principais debates políticos nacionais como também ocuparam cargos-chave nos ministérios da saúde e educação. (MESQUIDA, 2009, p.32) Dom Leme, na condição de arcebispo do Rio de Janeiro era o líder da Igreja católica no processo de renovação e crescimento do catolicismo. Ele considerava a atividade intelectual como fundamental e por isso deu amplo apoio às iniciativas de Figueiredo no âmbito cultural.

É através da revista $A$ ordem que Jackson de Figueiredo publicou uma série de artigos que meses mais tarde foram transformados no livro acima mencionado: A Reação do Bom Senso (FIGUEIREDO,1922). Nestes artigos encontram-se relatados os eventos que resultaram na origem da UCM, assim como pode-se perceber o papel de Jackson no incentivo e propagação das ideias defendidas pelos militares católicos, bem como o porquê da exaltação deste autor nas páginas de $\mathrm{O}$ Centurião.

A Reação do Bom Senso aponta a origem da UCM no ano de 1922. O seu surgimento está relacionado com o contexto de crise da Primeira República e com a demanda por parte da Igreja católica de um maior protagonismo na vida pública brasileira.

\section{A UCM e a campanha presidencial de 1922}

Comecemos pela crise vivida nos anos 1920. O biênio 1921-1922 é marcado por uma longa campanha presidencial, a qual ficou conhecida na historiografia como o berço do tenentismo (PRESTES, 1994, p.58).

Nesta disputa estava o mineiro Arthur Bernardes, candidato do governo Epitácio Pessoa, contra Nilo Peçanha, o candidato da chapa de oposição conhecida como Reação Republicana. Durante este embate, divulgaram, no jornal Correio da Manhã, cartas ofensivas ao exército que supostamente teriam sido escritas 
pelo candidato governista Arthur Bernardes. Estas cartas dividiram as forças armadas, de modo que o apoio a Nilo Peçanha cresceu especialmente entre os militares de baixa patente.

Em 05 de julho de 1922, ocorreu o primeiro dos levantes tenentistas, mas este não obteve sucesso em função da alta hierarquia das forças armadas ter se mantido ao lado do governo (PRESTES, 1994, p.60).

Apesar dos conflitos, Arthur Bernardes venceu as eleições, tomou posse e governou de novembro de 1922 a novembro de 1926. Para isto, contou com o significativo apoio dos movimentos católicos, que seguindo a orientação da Igreja buscavam aproximação com o governo. Bernardes recebeu apoio desde o período da campanha (AZZI, 1977, p.70).

A frente do movimento de apoio católico a figura de Arthur Bernardes estava Jackson de Figueiredo. O líder do centro Dom Vital definia-se como um reacionário viii, um seguidor do pensamento contrarrevolucionário elaborado após a revolução Francesa.

Seguindo esta linha de pensamento, ele apontou que os levantes tenentistas e a candidatura de Nilo Peçanha significavam a chegada ao Brasil de princípios revolucionários anticristãos oriundos da maçonaria, do liberalismo, do bolchevismo, do iluminismo, do antinacionalismo e do anarquismo. ${ }^{\text {ix }}$

Aos católicos caberia o exercício da contrarrevolução. A liderança da resistência estaria reservada aos católicos porque a doutrina católica seria a que mais fortaleceria a autoridade, a que mais criaria consciência de respeito à lei e a que ofereceria o maior fundamento ao Estado.

O Bernardismo seria merecedor de apoio, por ser o legítimo representante das forças conservadoras da nação, enquanto, a campanha presidencial, somente teria transformado o país num lugar de caos e de ameaça, por causa do longo processo de descristianização pelo qual o Brasil estaria passando desde o advento da República; Quando o ensino teria se tornado leigo, os jornais anticristãos e o exército distanciado da sua tradição de proximidade para com a cruz (FIGUEIREDO, 1922, p.25).

Para o líder do centro Dom Vital, a solução para a crise vivenciada pelo país passava pela luta pela palavra:

\begin{abstract}
A verdade é que as chamadas classes dirigentes vão degradando o nosso povo cada vez mais sistematicamente pela escola sem Deus, a imprensa licenciosa, o livro imoral. A verdade é que nunca, no Brasil, a palavra esteve tão escravizada ao mal e a serviço de tantos homens indignos dela. Mas somente ela poderá salvar-nos, por isto mesmo que ainda não baixamos à irracionalidade (FIGUEIREDO, 1922, p. 28).
\end{abstract}

\title{
A Benção das Armas: Momento fundador da UCM ${ }^{x}$
}

Além da fé no poder da palavra, no livro A Reação do Bom Senso, nos capítulos finais, Figueiredo (1922) apresentou mais motivos para entusiasmar os seus seguidores. Para o autor, a reação do bom senso 
nacional já havia se iniciado, nunca teria sido tão grande o movimento intelectual católico e no exército havia bons militares, não somente os maus.

Os bons militares seriam os católicos, uma maioria em movimento de crescimento que impediria a vitória dos revolucionários tenentistas. Dentre os católicos militares, o autor dá enfoque a um grupo, que na procissão eucarística do Centenário da Independência realizou uma cerimônia: A Benção das armas, evento símbolo da união entre a cruz e a espada. Trata-se de uma alusão a um dos momentos fundadores da UCM, ou melhor, as origens da UCM estão na cerimônia da Benção das armas. No ano de 1922, oficiais militares demonstraram publicamente a sua fé na ocasião da procissão eucarística do centenário da independência.

Tal fato teve uma boa repercussão entre os que resistiram ao movimento tenentista e em 1924, no jubileu do cardeal Arcoverde, 3000 militares comungaram publicamente na praça da república, na primeira páscoa coletiva. Naquele mesmo ano, formou-se o primeiro núcleo da UCM e em 1926, a associação foi oficializada (CENTURIÃO, 1929, p. 3).

Os membros da UCM afirmavam ser necessário criar uma cultura religiosa para combater a anarquia na sociedade e no exército. Defendiam também o crescimento de uma imprensa católica, a implementação do ensino religioso, o fortalecimento do nacionalismo e alterações na legislação constitucional que permitissem uma recristianização da sociedade brasileira (CENTURIÃO, 1928b, p. 20).

Desta forma, realizou-se a partir da UCM uma campanha pela recristianização do exército que se daria através da educação religiosa católica e pela volta da assistência religiosa nas forças armadas por meio do serviço de capelania ${ }^{x i}$. Assim, entendia-se que o exército poderia exercer com plenitude o papel de uma escola de ordem e disciplina que salvaria o país do espírito laico e ateísta republicano (CENTURIÃO, 1928c, p. 9).

A formação da UCM se deu em meio a um período de forte agitação e indisciplina dentro do exército. A criação deste grupo recebeu forte apoio da alta hierarquia militar, cujos membros estavam frequentemente envolvidos nas cerimônias religiosas e cívicas promovidas pela associação.

A cúpula do exército enxergou nesta associação um meio de disciplinar as forças armadas e conter o tenentismo através do binômio educacional religião católica-nacionalismo, e para tal contou com o apoio das autoridades eclesiásticas.

Deste modo, por meio da UCM, os interesses militares fundiram-se com os interesses políticos e culturais de afirmação social da Igreja católica. O uso da educação como meio para impor disciplina é uma prática adotada pelo exército desde o período imperial (ALVES, 2002, p.90). O diferencial apresentado pela UCM é a centralidade atribuída ao fator catolicismo como o meio para a efetivação deste controle.

O movimento tenentista, fator que impulsionou o surgimento da UCM, se desarticulou e desapareceu ao longo da década de 1930. Por sua vez, a UCM cresceu durante a era Vargas e no ano de 
1944 obteve a aprovação de uma lei que implementou o serviço de assistência religiosa ao exército, uma das principais bandeiras do grupo católico militar.

A política autoritária varguista ao buscar apoio na igreja e no exército (HORTA, 1994, p.99), fortaleceu esta associação militar católica que ganhou cada vez mais influência dentro das forças armadas (O BOM SOLDADO,1938, p. 2).

Desta maneira, a UCM se consolidou e promove comemorações religiosas e cívicas entre os militares e seus familiares até os dias de hoje. Uma das suas sedes se localiza na rua São José, número 90, no centro do Rio de Janeiro.

\section{Aspectos teóricos: A UCM e o seu papel enquanto aparelho privado de hegemonia conservadora}

A partir de qual perspectiva teórica enxergamos a UCM? O que significa o seu projeto educacional? Como podemos compreender o papel do periódico $O$ Centurião? E Jackson de Figueiredo, qual é a sua função?

As respostas para as perguntas acima passam por um filósofo italiano chamado Antônio Gramsci e pelos seus conceitos de Estado, sociedade civil, sociedade política e aparelho privado de hegemonia.

Para Gramsci (1978, p.11), o Estado é uma instituição que se sustenta através de dois pilares: a força e o consenso. A sociedade é, eis a complexidade, para fins didáticos, dividida em: sociedade civil e sociedade política. A sociedade política é aquela que exerce seu poder através do Estado de uma forma direta, enquanto a sociedade civil é aquilo que se entende como aparelho privado de hegemonia, privado porque é particular, a sua legitimidade não provém do Estado.

No entanto, a dicotomia entre sociedade civil e sociedade política é apenas teórica, ilustrativa, porque a sociedade é concebida por Gramsci como uma totalidade, isto é, a sociedade é um conjunto de pessoas e não podemos considerar que haja uma cisão entre a dimensão estatal e a privada, haja vista que estas esferas se interpenetram e influenciam reciprocamente em um movimento dialético.

Entrando na especificidade da nossa questão, os membros da UCM, por exemplo, são simultaneamente membros da sociedade política e membros da sociedade civil. São membros da sociedade política enquanto membros do exército e membros da sociedade civil enquanto membros da associação católica militar.

As normas e leis dispostas pela sociedade política interferem diretamente na sociedade civil organizada, isto é, nos aparelhos privados de hegemonia. Por outro lado, estes aparelhos privados de hegemonia tentam, por sua vez, interferir na sociedade política para que o Estado atue em favor dos seus grupos sociais. 
Dentro desta perspectiva teórica, o político ganha centralidade e está em toda parte, incluindo a sociedade política, isto porque as instituições estatais não podem ser compreendidas como apartadas do mundo cultural, especialmente nos estados democráticos capitalistas onde o fator político (leia-se o fator convencimento e as ideologias que o sustentem) está em forte evidência como fundamento daquilo que Rousseau (2016) chama de Contrato Social. ${ }^{\text {xii }}$

Como bem colocou Giovanni Semeraro (1999, p.47), os estudos de Gramsci colocam o político contra o economicismo, assim como o espírito de iniciativa contra uma visão teleológica da história. O poder passa a ser visto como algo descentralizado e reconhece-se o pluralismo social, superando a divisão mecânica entre governantes e governados, entre massas e intelectuais.

Queremos acrescentar que compreender a UCM como um aparelho privado de hegemonia (GRAMSCI, 1978), auxilia na compreensão de que a hegemonia conservadora católica, exercida nos anos 1930 e nas décadas subsequentes, não foi uma obra do acaso. Foi um projeto. Entender como este projeto foi engendrado e executado nos mínimos detalhes, permite a desnaturalização das vitórias conservadoras, assim como historiciza uma série de valores ainda presentes no campo educacional.

Na década de 1920, o campo militar estava distante do catolicismo, o conservadorismo católico era periférico e sequer havia serviço de capelania nas forças armadas. A UCM, enquanto aparelho privado de hegemonia, construiu, ao longo de décadas, um consenso conservador católico dentro do campo militar e este se reproduziu em uma ação educativa nacional, através da disciplina de educação moral e cívica, quando os militares assumiram a direção da sociedade política na década de 1960.

$O$ Centurião por sua vez, foi um aparelho tático difusor das ideias e ações determinadas pelo aparelho estratégico, ou seja, a UCM, o órgão diretivo da atuação católico-militar.

E quanto à articulação católico-militar? Já contextualizamos a origem do interesse militar na difusão dos valores católicos como meio disciplinar em oposição ao tenentismo. Mas, quais eram os interesses católicos nesta associação? Por qual razão a UCM encontrou amplo apoio nas mais altas hierarquias eclesiásticas?

Responder a estas questões exige um recuo no tempo para que possamos compreender o projeto político e cultural da Igreja católica bem como o que queremos dizer quando utilizamos a expressão pensamento conservador.

\section{O Conceito de Conservadorismo e A Igreja católica}

Iniciemos pelo conceito de conservadorismo. Esta noção é alvo de inúmeras controvérsias teóricas, contudo o objetivo deste trabalho é demonstrar a conexão entre o pensamento conservador e o projeto político-educacional da Igreja católica, haja vista que assim auxiliamos na construção de referenciais que 
permitam compreender as ações efetuadas por esta denominação religiosa que sempre foi, no Brasil, uma agente política de alta relevância.

Aquilo que de fato nos interessa é que seja possível compreender que as ações conservadoras católicas efetuadas no Brasil fazem parte de uma disputa global e estão relacionadas a uma linhagem política que remonta aos fins do século XVIII e já inspirou dezenas de experiências autoritárias em diversos países como: Franquismo, Salazarismo, Fascismo, Nazismo, dentre outros.

É a conjugação frequente entre autoritarismo, violação à liberdade de expressão e intolerância religiosa com o pensamento conservador que tornam necessário estarmos atentos às características desta forma de pensar e agir politicamente em sociedade.

As primeiras perguntas que os interessados nesta temática fazem são: $\mathrm{O}$ que se quer dizer com a expressão Conservadorismo? O que significa ser Conservador? Como estes conceitos podem ajudar os estudiosos na compreensão dos fenômenos sociais?

Para Karl Mannheim (1972, p.88), o Conservadorismo é um fenômeno histórico e sociológico. A sua origem histórica está no contexto pós-revolução francesa quando, de forma consciente e reflexiva, surgiu um contra-movimento em oposição ao movimento progressista e racionalista proveniente do iluminismo. Este movimento depende sempre de um conjunto concreto de circunstâncias, de tal modo que não podemos saber, previamente, como se efetivará a sua ação no sentido político.

Sob o ponto de vista social, Mannheim (1972, p.90) afirma que o conservadorismo está estreitamente ligado ao mundo moderno e industrializado quando a situação das forças histórico-sociais deixa de ser estática e passamos a ter um processo dinâmico de mudança relacionada com o aprofundamento das diferenciações sociais e com o surgimento de diferentes classes. Sendo que tais classes têm ação diversa na sociedade, ou seja, enquanto algumas lutam pela mudança social, outras lutam para retroceder. A esta diferenciação social então corresponde também a uma diferenciação política e a uma diferenciação cultural, a qual o autor designa como estilo de pensamento, ou seja, uma forma de pensar que se manifesta nos mais variados campos da cultura como na arte e na literatura.

Em resumo, o Conservadorismo é um estilo de pensamento com uma origem histórica (pósrevolução francesa) e sociológica (relacionada com a Revolução industrial, a crescente diferenciação das classes sociais e aos movimentos que lutaram a favor do status quo impedindo mudanças que permitam ascensão social e redefinição das hierarquias) bem definidas.

A Igreja Católica se integra ao pensamento conservador desenvolvido no pós-revolução francesa porque almeja reverter as mudanças políticas operadas pelo movimento revolucionário francês. Lembremos que os revolucionários franceses aboliram os privilégios do clero e causaram uma série de prejuízos financeiros à Igreja católica. 
Logo, intelectuais católicos e membros da igreja passaram a ser influenciados pelos textos contrarrevolucionários de autores como Edmund Burke (1790) e Joseph de Maistre (1797). Algumas características do pensamento destes autores apontam: 1) apego ao passado como modelo; 2) valorização da nação; 3) ênfase no concreto em contraposição ao abstrato; 4) a colocação das relações sociais externas subordinadas ao princípio da ordem e da disciplina. Neste último caso, a harmonia entre a liberdade subjetiva e a ordem externa seria garantida por Deus e pela Nação.

Na segunda metade do século XIX, tivemos a formulação de diretrizes intelectuais claras por parte da hierarquia da igreja católica, estamos nos referindo às encíclicas: Quanta cura (elaborada pelo Papa Pio IX em 1864) e Rerum Novarum (elaborada pelo Papa Leão XIII em 1891).

Estes documentos conclamaram os intelectuais a aderir à ortodoxia católica, reforçaram o apego à tradição, à ordem, à disciplina e à autoridade, assim como os incentivaram a uma postura política mais ativa.

Aderindo ao pensamento conservador, em especial àquele elaborado por Joseph de Maistre, católicos de todo mundo passaram a se enxergar numa cruzada contra os ideais iluministas. O mundo estaria em uma crise de valores que somente poderia ser solucionada pela adesão aos ideais católicos e pela rejeição das ideologias baseadas num racionalismo abstrato que teria enfraquecido às autoridades e lançado o mundo num caos social.

Esta política católica, de maior apego à ortodoxia ${ }^{x i i}$ e de combate intelectual às ideologias decorrentes do Iluminismo ${ }^{\text {xiv }}$, chegou ao Brasil no período Republicano, quando a separação entre Igreja e Estado permitiu uma maior liberdade de organização e iniciativa aos católicos.

Assim, na década de 1920, Dom Leme está engajado num esforço para fortalecer o catolicismo no Brasil. O seu projeto de ação está alinhado com a política filosófica internacional da Igreja Católica e vê no combate de ideias um dos principais caminhos. É por isso que em 1922, Jackson de Figueiredo recebe apoio para criar o Centro Dom Vital e a revista A Ordem.

O Centro Dom Vital é um aparelho de hegemonia utilizado pelos católicos leigos sob o incentivo das mais altas hierarquias católicas. A revista A Ordem é um aparelho a serviço do Centro Dom Vital. Contudo, O Centro Dom Vital é um órgão de caráter mais estratégico enquanto A Ordem é um instrumento tático de divulgação. Ou seja, podemos fazer uma analogia com a UCM e O Centurião. A UCM como órgão estratégico e O Centurião como órgão tático.

A diferença é que enquanto O Centro Dom Vital e A Ordem estão sob domínio da Igreja Católica, a UCM e o Centurião representam uma aliança entre católicos e militares de maneira que existe uma clara influência católica, mas não há uma subordinação do campo militar, haja vista que os membros da UCM e os redatores de $O$ Centurião são todos militares. Jackson de Figueiredo inspirou a UCM e divulgou as ações dos militares católicos, mas não exerceu direção sobre a associação. 
O interesse católico era angariar apoio social para os seus projetos políticos e educacionais, enquanto o interesse militar era o reforço da ordem e da disciplina no campo militar. Assim, formou-se uma aliança que, com poucas rupturas, subsiste até os dias atuais.

\section{O papel dos intelectuais}

Conforme o exposto acima, católicos e católicos-militares firmaram uma aliança baseada em interesses convergentes a ser conquistados mediante uma ação educacional que combatesse determinados sistemas de pensamento, assim como promovesse a disciplina e o respeito às autoridades. Neste contexto de ação educacional e combate de ideias, torna-se necessário esclarecer como o presente trabalho entende o papel dos intelectuais, sejam os intelectuais católicos, sejam os intelectuais militares. ${ }^{\mathrm{xv}}$

Primeiramente, compreende-se o conceito de intelectual a partir do referencial Gramsciano. Isto significa que todo ser humano é percebido como um intelectual, mas que nem todos exercem o papel de intelectual na sociedade. Ao analisar a UCM, o foco foi dirigido àqueles que eram percebidos como intelectuais no período estudado. Como colocou Gramsci (1978, p.9), existem graus diversos de atividade intelectual e a maior atenção deste trabalho foi dirigida àqueles que as fontes indicaram como os mais influentes na direção da associação, seja de forma direta, seja de forma indireta.

No caso da origem da UCM, durante a década de 1920, o intelectual que teve maior influência foi Jackson de Figueiredo. Seu nome é frequentemente exaltado em o Centurião. Jackson de Figueiredo, como líder leigo do Centro Dom Vital e da revista A Ordem, estava no plano superestrutural chamado de sociedade civil, trabalhando na função de hegemonia, ou seja, na busca pelo consenso espontâneo. Isto no período entre 1922 e novembro de 1925.

Já entre novembro de 1925 e novembro de 1926, Jackson passou a estar presente nos dois planos da superestrutura, pois acumulou as atividades supracitadas (no plano da sociedade civil) com a função de chefe de censura do Rio de Janeiro (no plano da sociedade política, ou seja, a função de domínio direto no aparato de coerção estatal).

A trajetória de Jackson de Figueiredo é bastante ilustrativa acerca da dialética entre sociedade civil e sociedade política e acerca do papel dos intelectuais como funcionários no âmbito das superestruturas, seja na obtenção do consenso espontâneo, seja na legitimação da coerção.

Os intelectuais católico-militares continham ambiguidade análoga a que Jackson de Figueiredo ostentou entre novembro de 1925 e novembro de 1926 porque os católicos militares, estavam ora como membros da sociedade civil, ora como membros da sociedade política, ou seja, ora trabalhando em busca do consenso espontâneo, ora trabalhando a legitimação da coerção. 
Através da obra de Jackson de Figueiredo e dos artigos escritos pelos mais diversos intelectuais militares em O Centurião, pode-se observar a afinidade entre o projeto educacional católico e o projeto educacional da UCM, ou seja, um projeto que entende a religião católica como condição fundamental para uma adequada formação moral e para a edificação de um povo nacionalista (ideias matrizes da disciplina Educação Moral e Cívica, tanto na década de 1930 quanto na década de 1960).

\section{O projeto educacional da UCM}

Quando falamos do projeto educacional da UCM, estamos tratando daquilo que pode ser vislumbrado através da obra de Jackson de Figueiredo e pelo observado nos exemplares de o Centurião publicados entre 1928 e 1929.

Segundo Carvalho (1987, p.73), os anos 1920 foram caracterizados por um consenso quanto ao poder atribuído à educação, no sentido de que católicos, positivistas e liberais estavam unidos em torno de um projeto cujo denominador comum era a ênfase no papel moralizador da educação. A partir de 1929, este consenso torna-se mais difícil por conta de um documento elaborado pelo Papa Pio XI: A Encíclica Divini Illius Magistri.

Através deste documento, as diferenças pedagógicas até então escamoteadas, passam a se tornar evidentes. Podemos exemplificar analisando que os católicos queriam ver o professor em uma posição de autoridade, moldando a prática educativa, enquanto os escolanovistas estavam interessados em formular os métodos educativos em função da natureza do aluno. Outra divergência estaria na questão da finalidade pedagógica, porque para os católicos haveria na educação um finalismo religioso e também uma busca por uma moral baseada no catolicismo, o que, por sua vez, feria a sensibilidade leiga dos escolanovistas. (Carvalho, 1987, p.73)

Estas divergências resultaram numa ruptura definitiva entre católicos e escolanovistas, em 1932, quando lançou-se o Manifesto dos Pioneiros da Educação Nova. O projeto educacional defendido por Jackson de Figueiredo e pela UCM é bem anterior a esta ruptura.

Tendo em vista que Jackson de Figueiredo e a UCM eram ortodoxos e falavam para um público católico, o teor das suas ideias educativas estava plenamente de acordo com a encíclica papal publicada em dezembro de 1929, sendo assim altamente representativas do pensamento católico defendido na década de 1930. Podemos até dizer que Jackson de Figueiredo e a UCM foram pioneiros da educação conservadora católica, manifestando-se muito antes do papa e dos pioneiros da Educação Nova. Isto significa que a oposição de ideias já existia e que o manifesto de 1932 foi mais uma consolidação de uma ruptura do que o início de uma fratura.

Desse modo, podemos nos questionar, quais eram as ideias educacionais defendidas pela UCM? 
A UCM, através de $O$ Centurião, defendeu não existir educação sem Moral e Religião. Sem religião se perderia a noção do justo e do injusto. O livro instrutivo mais eficaz seria o crucifixo de onde se poderia extrair muitos conhecimentos. Através deste livro os alunos seriam levados à perfeição. $\mathrm{O}$ conhecimento acerca do sobrenatural permitiria conhecer melhor o natural e o científico. Assim, a fé permitiria conhecer as verdades científicas de forma mais adequada e desta forma, o cientista católico seria superior ao cientista ateu.

Para o Centurião, o ensino brasileiro leigo abre espaço para cientistas materialistas ateus e incompetentes que degradam o conhecimento do povo e levam o ensino brasileiro a uma situação deplorável.

A França é para a UCM, o maior exemplo dos perigos contidos na educação leiga. Desta feita, O Centurião descreve a Universidade francesa como uma escola do desequilíbrio. Na França os professores estariam a negar os princípios morais e se recusando a inculcar nos meninos e meninas o respeito à família, às tradições dos antepassados e o amor à Pátria, ou seja, a falta do ensino religioso ameaçaria valores muito caros aos conservadores.

Além disso, segundo $\mathrm{O}$ Centurião, a indiferença à religião acaba por se transformar em ódio à religião, levando todos à ruína e criando gerações de infelizes, criminosos, suicidas e cínicos.

Por fim e não menos importante, O Centurião afirma, assim como Jackson de Figueiredo (Ibid.) em sua obra principal, que a educação deveria seguir os preceitos católicos em respeito aos direitos da maioria.

\section{Conclusão}

As linhas iniciais deste trabalho prometeram apresentar uma associação de militares católicos conhecida como UCM. Estudamos a sua origem e vimos que o seu surgimento está relacionado a uma confluência de interesses entre a Igreja Católica, ávida pela afirmação dos seus projetos políticos e culturais, e o exército, ansioso por debelar o movimento tenentista e garantir a manutenção da ordem e disciplina dentro do campo militar.

Também estabelecemos uma relação entre os dados empíricos obtidos em $O$ Centurião, órgão de imprensa oficial da UCM, e os conceitos Gramscianos de Estado, sociedade civil e sociedade política. O mesmo foi feito com as informações obtidas nas obras de Jackson de Figueiredo, quando tornou-se necessário fazer algumas breves considerações teóricas acerca dos intelectuais e o seu papel social.

Sendo assim, fica evidente que a UCM atuou como um aparelho privado de hegemonia em favor de um projeto educacional conservador católico que pregando o respeito à autoridade, caiu na armadilha de 
ser defensora do autoritarismo, uma vez que de acordo com a visão ali empreendida o aluno deve ser moldado, independente da sua história de vida e contexto social.

Contudo, ainda mais grave que este autoritarismo pedagógico é a visão religiosa imprimida e difundida por esta associação. Podemos com certeza afirmar que a UCM defendia uma educação católica fundamentalista e teocrática.

Quando utilizamos a palavra fundamentalista, o fazemos em razão da UCM afirmar que não existe educação sem religião. Este posicionamento despreza todas as formas educativas não cristãs, ou melhor, não católicas. Qualquer posicionamento filosófico divergente como o dos escolanovistas, ou ateístas, recebe a qualificação de inimigo da sociedade e da família. Fundamentalista é aquele que trata assuntos sociais sob o prisma de dogmas inquestionáveis, escapando do debate racional sustentado por argumentos científicos.

$\mathrm{O}$ direito à laicidade se constitui em duas garantias. A primeira diz respeito à igualdade de tratamento que deve ser oferecida às mais diversas religiões por parte do Estado, que deve ser neutro relação às crenças religiosas, o que inclui o ateísmo. A segunda garantia oferecida pelo direito à laicidade, é a liberdade religiosa, ou seja, o exercício da sua crença sem constrangimentos.

A educação sob o viés defendido pelos católicos e católicos-militares acabava por colocar em risco o Estado democrático de direito porque afrontava diretamente o princípio da laicidade ao argumentar que o catolicismo deveria pautar a educação pública por ser a religião da maioria do povo brasileiro.

O uso da palavra teocracia se justifica porque ainda sob o argumento de que o Brasil era um País católico, defendia-se que as práticas governamentais deveriam estar sujeitas aos princípios do catolicismo.

O autoritarismo destas concepções não torna espantoso que Jackson de Figueiredo tenha se tornado chefe de censura durante o quadriênio governamental de Arthur Bernardes, assim como não surpreende que a UCM tenha conquistado o direito à assistência religiosa no ano de 1944 (período da ditadura do Estado Novo) e assim tenha aumentado o seu poder de influência junto ao campo militar. Da mesma forma que também não causa espanto que durante a ditadura civil militar implantada em 1964, tenha sido implantada em todo o País uma disciplina baseada na moral católica: a famosa educação moral e cívica.

O que há em comum nos fatos acima narrados? Todas estas conquistas do projeto conservador católico aconteceram em períodos de notório autoritarismo. Personagens vinculados aos ideais católicos conservadores ascenderam aos mais altos cargos em períodos ditatoriais.

O desrespeito à laicidade não se constitui apenas no ataque direto às minorias. Quando o agente público demonstra no exercício das funções estatais a sua preferência religiosa, acaba por passar de maneira tácita ao conjunto da sociedade, uma mensagem que demarca simbolicamente quem são os cidadãos preferenciais e quem são os subcidadãos, àqueles que não merecem igualdade, no máximo tolerância. 
O desrespeito à necessária neutralidade do Estado naquilo que diz respeito as crenças religiosas, não somente é um desrespeito à constituição, que assegura a separação entre Estado e religião, como também é uma forma de subalternizar o outro, aquele que pensa diferente. Fica o alerta.

\section{Referências:}

ABREU, Lousi Storni Vasconcelos. Educação Moral e Cívica: para além de um projeto educacional, um projeto de nação. XXVIII Simpósio Nacional de História, Florianópolis, 2015, p.10-20.

ALVES, Claudia Maria Costa. Cultura e política no século XIX: o exército como campo de constituição de sujeitos políticos no Império. Bragança Paulista: EDUSF, 2002.

ARMSTRONG, Karen. Em Nome de Deus: o fundamentalismo no judaísmo, no cristianismo e no islamismo. Rio de Janeiro: Companhia das Letras. 2001.

AZZI, Riolando. O início da restauração católica no Brasil, 1920-30 (I-II). In: Síntese política e econômica. n. 10 - 11, SP, 1977. P.70-79

BOURDIEU, Pierre. A economia das trocas simbólicas. 6ªEdição São Paulo: Perspectiva, 2007.

BURKE, Edmund. Reflexões sobre a Revolução na França; SOARES, José Miguel Nanni. (Trad.)- $1^{\text {a }}$ ed.- São Paulo: EDIPRO, 2014.

CARVALHO, Marta Maria Chagas de. Pelo ensino público, leigo e gratuito. Revista da Universidade de São Paulo. São Paulo, nº: 71-83, Jul./set.1987.

CUNHA, Luís Antônio. Sintonia oscilante: religião, moral e civismo: 1931-1997, cadernos de pesquisa. SP, $\mathrm{n}^{\circ}$ 131, maio/agosto, 2007.

FIGUEIREDO, Jackson. A reação do bom senso. Edição do anuário do Brasil. Rio de Janeiro. 1922. GRAMSCI, Antônio. Os intelectuais e a organização da cultura. Rio de Janeiro: Ed. Civilização Brasileira, 1978.

MAISTRE, Joseph. Considerações sobre a França. Biblioteca Nacional de Portugal.

MANNHEIM, Karl. Ideologia e Utopia. Rio de Janeiro: Zahar Editores, 1972.

MESQUIDA, Peri. A educação na Restauração Lemista da Igreja: a missão de Tristão de Athayde e Stella de Faro no ministério da educação e saúde pública: 1934-1945. Revista Diálogos educacionais. Curitiba, 2009.

HORTA, José Silvério Baía. O hino, o sermão e a ordem do dia: regime autoritário e a educação no Brasil (1930-1945). Rio de Janeiro, Editora UFRJ, 1994.

O BOM SOLDADO: Boletim de Informações da União Católica dos Militares. Rio de Janeiro, Biblioteca Nacional, 1938, nº 1, Julho, 42p.

O CENTURIÃO: Órgão da União Catholica Militar. Rio de Janeiro: Biblioteca Nacional, 1928a, nº 2 , julho, $40 \mathrm{p}$.

O CENTURIÃO: Órgão da União Catholica Militar. Rio de Janeiro: Biblioteca Nacional, 1928b, nº 5 , Setembro, $36 \mathrm{p}$.

O CENTURIÃO: Órgão da União Catholica Militar. Rio de Janeiro: Biblioteca Nacional, 1928c, nº 9 , mês Dezembro, 38p.

O CENTURIÃO: Órgão da União Catholica Militar. Rio de Janeiro: Biblioteca Nacional, 1929, $\mathrm{n}^{\circ} 12$, Abril, $42 \mathrm{p}$.

PELEGRINI, Thiago. Criação e funcionamento da comissão nacional de moral e cívica. Revista espaço acadêmico, $n^{\circ} 202,2018$. 
PLÁCIDO, Gilmara Duarte. Educação, Civismo e religiosidade durante a ditadura civil-militar (1964-1985). X ANPED, 2014.P.23-29

PRESTES, Anita Leocádia. Os militares e Reação Republicana. Rio de Janeiro: Ed.Vozes, 1994. ROUSSEAU, Jean-Jacques. Do contrato social: princípios de direito político. Machado, Antônio P. (Trad.) - Rio de Janeiro: Nova Fronteira, 2016.

SEMERARO, Giovanni. Gramsci e a sociedade civil: cultura e educação para a democracia. Petrópolis, RJ: Vozes, 1999.

SEPÚLVEDA, José Antônio. O papel da escola superior de guerra na projeção do campo militar sobre o campo educacional. 2010. 233 f. Tese (Doutorado em Educação) UFRJ, Rio de Janeiro.

\section{Notas:}

\footnotetext{
i Doutorando em Educação pela UFF, Professor de História na rede FAETEC e na Prefeitura de Duque de Caxias. Email: lessatorres@yahoo.com.br

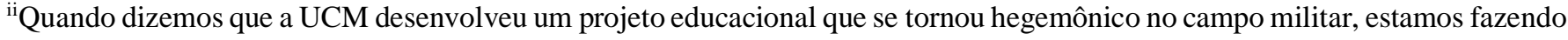
alusão ao fato de que na década de 1920, período de surgimento da associação, o Positivismo se apresentava como força dominante no exército e demais corporações militares, o que significa que os valores católicos eram, àquela altura, periféricos. A respeito da influência do positivismo no exército, Cf. Sepúlveda (2010,p.40-55). A associação de valores religiosos com o militarismo não é, portanto, algo que deva ser naturalizado, pelo contrário, deve ser compreendida dentro de uma visão histórica que resgate a construção deste vínculo.

iii Quando usamos a expressão campo militar, estamos fazendo uso do conceito de Campo de Bourdieu. Em linhas gerais, o termo Campo diz respeito a um microcosmo da sociedade que possui certo grau de autonomia, assim como regras peculiares de funcionamento quando comparadas às demais esferas da sociedade. (BOURDIEU, 2007, pp.30-35) O conceito de Campo, desta forma, constitui um recurso teórico que aponta ao cientista social que a compreensão de determinados fatos e comportamentos, exige uma atenção para determinadas especificidades. Sendo assim, estudar fenômenos relacionados aos militares, pressupõe uma atenção especial ao contexto histórico em que se construiu o campo militar. O mesmo é válido para aquele que pretende estudar fenômenos religiosos, ou seja, é necessário um foco específico para o contexto sobre o qual se construiu o campo religioso. No caso deste trabalho, estamos lidando com uma associação que representa uma interseção entre o campo religioso e o campo militar, logo será preciso visualizar ambos os contextos de maneira que seja possível compreender como se deu a convergência entre a Igreja católica e os militares, em especial com o exército.

iv O papel da disciplina Educação Moral e Cívica na difusão de valores conservadores vinculados ao nacionalismo e, em especial, ao catolicismo, já foi amplamente estudado e demonstrado na historiografia. Para maiores informações, Cf. ABREU (2014, pp.10-20); CUNHA (2007, pp.28-35); PELEGRINNI(2018, pp.30-36); PLÁCIDO (2015, pp.23-29); SEPÚLVEDA (2010, pp.70-74)
} 


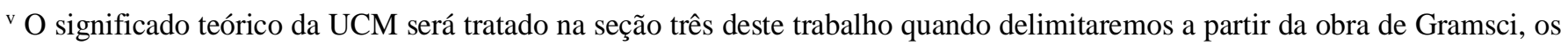
conceitos de Estado, Sociedade civil, Sociedade Política, Hegemonia e Aparelho privado de hegemonia.

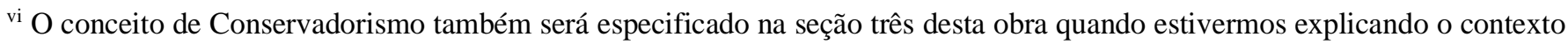
que pautou a ação política da Igreja Católica no Brasil nos anos 1920. Por ora, atentemos apenas para o fato de que compreendemos o Conceito de Conservadorismo como um estilo de pensamento que consolida suas principais características a partir de 1790 como uma forma de oposição ao conjunto de acontecimentos e políticas públicas denominadas como Revolução Francesa. Estilo de pensamento é uma noção que tomamos de Mannheim (1972, pp. 92-95) e que, em linhas gerais, diz respeito a uma forma de compreender o mundo que se manifesta nos mais variados domínios da ação humana como: política, literatura, etc. O estilo de pensamento conservador irá se apresentar em vários países e épocas, respeitando, por óbvio, as especificidades culturais de cada sociedade e período histórico. O valor desta noção está em permitir que enxerguemos a ação da UCM dentro de um contexto mais amplo, isto é, como um fenômeno global e não apenas como algo circunscrito às especificidades brasileiras . vii $\mathrm{O}$ conceito de intelectual será abordado com detalhes na seção três deste trabalho a partir do arcabouço teórico Gramsciano (1978, pp. 7-15).

viii Entendemos que não há distinção política e filosófica que fundamente uma distinção entre reacionários e conservadores. O próprio Jackson de Figueiredo utiliza estas expressões como sinônimas em A Reação do Bom Senso. A diferenciação entre estes termos surge posteriormente à derrota nazista na segunda guerra mundial quando conservadores passam tentar se distanciar da derrotada experiência da extrema- direita.

ix Neste parágrafo, quando usamos os termos: anticristãos e antinacionalismo, estamos utilizando as expressões na forma como elas foram colocadas por Jackson de Figueiredo em a Reação do Bom Senso.

${ }^{x}$ Tomando uma terminologia comum ao campo do direito, fazemos uma distinção entre o campo da formalidade e o campo da eficácia (campo da realidade prática). Isto significa que a UCM nasce formalmente em 1926, entretanto, do ponto de vista prático, esta associação entre militares e católicos surge em 1922, durante a cerimônia de Benção das armas, quando os militares católicos passam a se enxergar como um grupo portador de uma identidade específica em relação aos demais militares. A Benção das Armas possui não apenas um significado religioso, mas também um significado político, isto é, ao pedirem publicamente a Benção das armas, os militares católicos estão desafiando a noção de laicidade então vigente e afirmando a sua principal agenda: a luta pelo retorno do serviço de assistência religiosa.

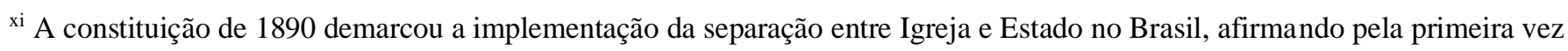
em nossa ordem jurídica o princípio da laicidade. Como consequência as forças armadas perderam o direito à assistência religiosa, tendo fim a capelania militar. O fim da assistência religiosa nas forças armadas causou insatisfação entre os militares católicos mais fervorosos, assim como indignou as autoridades eclesiásticas católicas. Em 1944, após mais de 17 anos de campanha da UCM, durante a vigência do Estado Novo, ocorreu o retorno do serviço de capelania religiosa nas forças armadas. Mesmo após o fim da ditadura Varguista, o serviço de capelania militar permanecerá sendo oferecido e garantido em todas ordens constitucionais subsequentes, haja vista o poder de influência da Igreja católica e de grupos militares católicos em favor deste serviço.

xii Acerca do Contratualismo, devemos lembrar que tratamos de um conceito político segundo o qual poder do Estado emana do povo, de tal forma que, de uma maneira direta ou indireta, os Estados democráticos, ou pretensamente democráticos, buscam, no mínimo, parecer em sintonia com a vontade da população como uma maneira de legitimar as suas ações. Acerca do contrato social, Cf. (ROUSSEAU, 2016, pp.111-114).

xiii Combatendo as interpretações populares da fé católica, tentando assim obter uma maior unidade doutrinária 
${ }^{\text {xiv }}$ Estamos nos referindo a sistemas filosóficos que em alguma medida são tributários do esforço racionalista iluminista e, por sua vez, tornaram-se alvo do conservadorismo católico como: o liberalismo, o Positivismo e o comunismo.

xv Acerca da historicidade da intelectualidade militar no Brasil, Cf. (ALVES, 2002, pp.90-102) 